\title{
Activated banana peel carbon: a potential adsorbent for Rhodamine B decontamination from aqueous system
}

\author{
Santosh Singh ${ }^{1} \cdot$ Amit Kumar $^{2} \cdot$ Himanshu Gupta $^{1}$ (i)
}

Received: 10 May 2020 / Accepted: 26 June 2020 / Published online: 9 July 2020

(c) The Author(s) 2020

\begin{abstract}
Among various environmental pollutants, dyes have been reported to contaminate a large quantity of surface water. Rhodamine B, a widely applicable basic dye, is known for its hazardous impact on environment. The present study proposes the application of readily available waste banana peels for the remediation of water contaminated with Rhodamine B. The potential of prepared material to decontaminate Rhodamine B was examined as the function of various parameters. Variation in adsorption time, dose of adsorbent, $\mathrm{pH}$ value, and initial concentration has been observed under the influence of diverse condition. Quantitative adsorption was observed at a contact time of $60 \mathrm{~min}$ with an adsorbent dose of $12 \mathrm{mg}$. An increase in the initial dye concentration resulted in the enhancement of adsorption capacity of adsorbent. The value of enthalpy change was observed to be $-8.95 \mathrm{~kJ} \mathrm{~mol}^{-1}$. The negative value indicates the exothermic removal of Rhodamine B from water. Various models were applied to explain thermodynamics and kinetics of the process. Adsorption kinetics was better explained with pseudo-second-order model, whereas adsorption mechanism by intra-particle diffusion model reveals that pore diffusion was not only the rate-controlling step.
\end{abstract}

Keywords Decontamination $\cdot$ Basic dye $\cdot$ Thermodynamics $\cdot$ Kinetics $\cdot$ Intra-particle diffusion

\section{Introduction}

The disposal of wastewater through various industries is a source of several hazardous pollutants which include toxic organic, inorganic, dissolved solids, dyes, acids, and bases, etc. (Kumar et al. 2019a, 2020a, b, c). The disposal of various kinds of persistent pollutants such as persistent organic pollutants (POPs), pentachlorophenols (PCPs), pesticides, heavy metals, and dyes has led to the reduction of freshwater content in the surrounding river or any water body (Kumar et al. 2014a, b, 2017a, b, c). Among all contaminants, dyes seem to be the most prominent as it can be easily recognized by human eye. It is due to the fact that water gets

Amit Kumar

amitkdah@nuist.edu.cn

$\triangle$ Himanshu Gupta

hims.research@gmail.com

1 Department of Chemistry, School of Sciences, IFTM University, Lodhipur Rajput, Moradabad 244102, U.P., India

2 Nanjing University of Information Science and Technology, School of Hydrology and Water Resources, Jiangsu 210044, Nanjing, China color in the presence of dyes (Kumar et al. 2019b). Dyes have been used in many industries such as paper, printing, textiles, plastics, cosmetics, and pharmaceutical industries (Yao et al. 2017, Kumar et al. 2020a). Over 10,000 types of dyes have been manufactured, and production is more than 70,000 tons per year worldwide (Zhu et al. 2017). Dyes are found to be toxic, non-biodegradable, and stable. These can be carcinogenic, genotoxic, mutagenic, and teratogenic in nature (Rahman et al. 2005; Yao et al. 2017; Zhu et al. 2017). A class of toxic organic dyes is Rhodamine, which is used in textile printing. Rhodamine is highly used due to its property to provide resistance to light, heat, rubbing, and washing. Among the different Rhodamines, Rhodamine B (RHB) is an aromatic, water-soluble, and basic dye (Salleh et al. 2011) which exists in two molecular forms cationic and zwitter ionic form (Chang and Cheung 1992). RHB is considered as toxic colorant due to its harmful effects on human beings such as allergic dermatitis, skin irritation, mutation, and cancer. Different remediation techniques such as flocculation, froth floatation, chemical oxidation, photolytic degradation, biological treatment, and adsorption have been adopted to remove toxic dyes from wastewater (Kumar et al. 2020b). Among these techniques, photocatalytic degradation 
of pollutants was quite popular in the recent years (Gupta 2016; Gupta and Gupta 2015a, b; Kumar et al. 2020b). The photocatalytic degradation of Rhodamine $\mathrm{B}$ is also reported by various environmentalists (Nagaraja et al. 2012; Sundararajan et al. 2017; Posa et al. 2016). The dye stability toward oxidizing agents and light limits its photodegradation. Moreover, the formation of different intermediates or metabolites causes a hazard to the environment and makes the water unsuitable for drinking (Yao et al. 2017; Mishra and Maiti 2016; Mishra et al. 2020; Gupta et al. 2004). Similarly, different methods applied to removal of dyes from water or wastewater are limited to some aspects which include high energy, chemical requirements, incomplete treatment, toxic waste generation, high operational or maintenance cost (Weis and Weis 2004). The most effective method to remove organic contaminants from aqueous medium was reported as adsorption (Rahman et al. 2005). Adsorption technique is perceived to be most feasible, effective, economic, competitive, and simple for remediation of various organic and inorganic pollutants (Yao et al. 2017). A variety of low-cost adsorbents such as waste banana pith, coir pith, oil palm nut shell, activated charcoal, mango seed, bottom ash, olive waste cakes, sewage sludge, acorns, and olive seeds, durian peel, coconut shells or palm seeds, orange rind, tea waste, vehicular tire, cotton, and apricot seeds have been used to adsorb various types of environmental pollutants (Gupta 2018; Paliwal et al. 2015; Salam and Buhari 2014; Gupta et al. 2004, 2005; Lafi 2001; Tan et al. 2008; Gupta and Gupta 2016a; Shaikh et al. 2011). India, the largest producer of banana, contributes about $27 \%$ of the total production of banana in the world (Mohapatra et al. 2010) and hence the largest producer of banana peels waste. In view of this, banana peel has been selected as a low-cost and highly abundant raw material for the preparation of activated carbon for the removal of RHB from aqueous systems. The kinetics and thermodynamics of a toxic dye, Rhodamine B, from aqueous medium by the application of low-cost activated banana peel carbon (ABPC) have been investigated in the present study. The work demonstrates the application of ABPC for removal of a toxic dye RHB from aqueous media. The study may serve as basis for production of ABPC on commercial scale and can be tested for treatment of various pollutants in industrial wastewaters.

\section{Materials and methods}

\section{Adsorbate and adsorbent}

RHB dye was purchased from RANKEM. The stock solution (1000 $\mathrm{mg} \mathrm{L}^{-1}$ ) was prepared by dissolving $0.1 \mathrm{~g}$ Rhodamine $\mathrm{B}$ dye in $100-\mathrm{mL}$ volumetric flask using double distilled water. All the other reagents used were of analytical grade. The activated carbon was developed using method applied in earlier studies (Gupta and Gupta 2016b). The adsorbent produced was sieved to the particle size of less than $75 \mu \mathrm{m}$ and was placed in a vacuum desiccator until required. Brunauer-Emmett-Teller (BET) equation was applied to determine the specific surface area (SSA) of the adsorbent. The determined SSA of ABPC was found to be $936.47 \mathrm{~m}^{2} \mathrm{~g}^{-1}$.

\section{Adsorption studies}

Rhodamine B adsorption onto ABPC was carried out at ambient temperature in batch mode. Thirty milliliters of prepared Rhodamine B solution $\left(100 \mathrm{mg} \mathrm{L}^{-1}\right)$ was placed in conical flask, and ABPC was added to the solution. The maintenance of $\mathrm{pH}$ of solution was performed with standard acidic $(1 \mathrm{M} \mathrm{HCl})$ and basic $(1 \mathrm{M} \mathrm{NaOH})$ solutions. The solutions were kept on a shaker for $120 \mathrm{~min}$. The filtration of samples was performed by Whatman filter paper, and remaining RHB concentration was analyzed. The dye samples were analyzed through UV-visible spectrophotometer using a wavelength of $545 \mathrm{~nm}$. The mass balance equation used to assess the adsorption of RHB per gram of adsorbent $\left(q_{\mathrm{e}}\right)$.

$q_{\mathrm{e}}=\left(C_{\mathrm{o}}-C_{\mathrm{e}}\right) \times \frac{V}{W}$

where $q_{\mathrm{e}}$ is adsorbate per gram of adsorbent; $C_{\mathrm{o}}$ is initial concentration of Rhodamine $\mathrm{B}$; $C_{\mathrm{e}}$ is concentration of Rhodamine $\mathrm{B}$ at equilibrium $\left(\mathrm{mg} \mathrm{L}^{-1}\right) ; V$ represents solution volume (L), and $W$ is adsorbent weight $(\mathrm{g})$.

The time of contact between adsorbent and adsorbate is an important parameter to examine the adsorption behavior of any pollutant on the prepared adsorbent. The effect of time for the removal efficiency of ABPC against RHB was determined for $0-120 \mathrm{~min}$. The effect of adsorbent amount on the adsorption of RHB on ABPC was observed with $1-20 \mathrm{mg}$ of the adsorbent for $30 \mathrm{~mL}$ of individual dye solution. The solution was kept on mechanical shaker for $60 \mathrm{~min}$. The $\mathrm{pH}$ effect was observed in the $\mathrm{pH}$ range $2-10$ for $60 \mathrm{~min}$. The effect of initial concentration of dye was studied in the range $10-120 \mathrm{mg} \mathrm{L}^{-1}$ for $60 \mathrm{~min}$.

\section{Assessment of best-fitting isotherm model}

Widely accepted Langmuir and Freundlich isotherms were used to assess adsorption of RHB (25-100 $\mathrm{mg} \mathrm{L}^{-1}$ ) on ABPC. The Langmuir isotherm predicts existence where no site of adsorbate molecule is interacting with each other; hence, monolayer coverage formation (Amarasinghe and Williams 2007) and Freundlich isotherm demonstrates multilayer process (Shaikh et al. 2011). The 
linear form of Langmuir adsorption isotherm followed by Freundlich isotherm for heterogeneous surfaces is as follows:

$\frac{1}{q_{\mathrm{e}}}=\left(\frac{1}{Q^{\circ} b}\right)\left(\frac{1}{C_{\mathrm{e}}}\right)+\left(\frac{1}{Q^{\circ}}\right) \quad$ [Langmuir isotherm equation $]$

where $Q^{\circ}$ and $b$ represent the monolayer adsorption capacity $\left(\mathrm{mg} \mathrm{g}^{-1}\right)$ and adsorbent affinity for adsorbate.

$\log q_{\mathrm{e}}=\log k_{\mathrm{f}}+\frac{1}{n} \log C_{\mathrm{e}} \quad$ [Freundlich isotherm equation]

where $\mathrm{n}$ and $\mathrm{K}_{\mathrm{f}}$ are adsorption intensity and adsorption capacity, respectively.

(a)

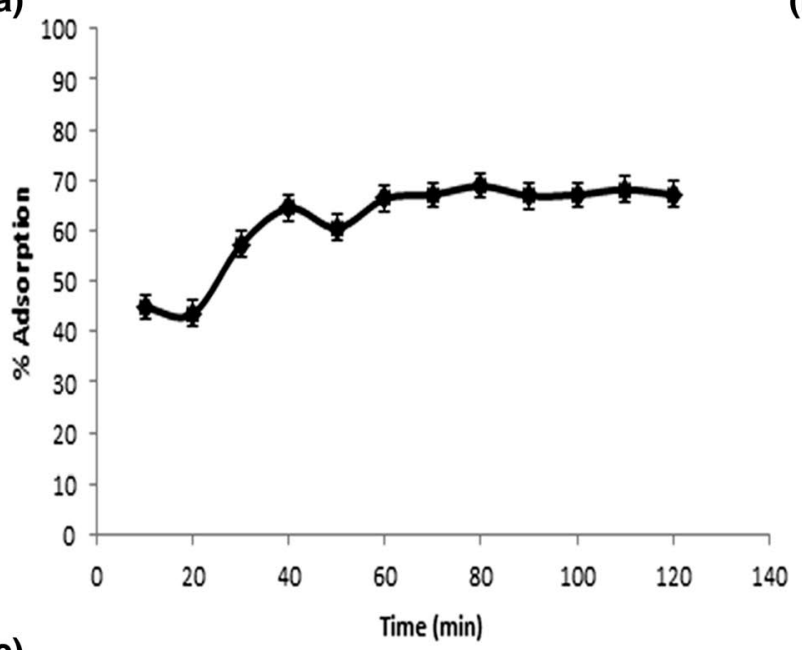

(c)

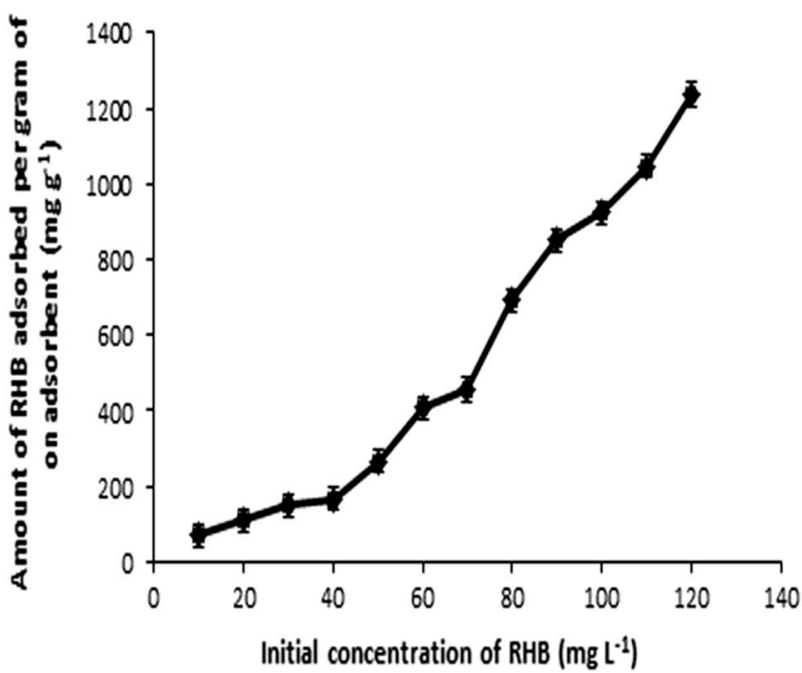

\section{Results and discussion}

\section{Effect of contact time}

The adsorption capacity increases with the contact time at constant temperature, $\mathrm{pH}$ as well as dose of adsorbent. It was observed that initially, adsorption occurs at rapid rate up to $60 \mathrm{~min}$. After $60 \mathrm{~min}$, there is no significant variation in adsorbate concentration and equilibrium in adsorption capacity is observed (Fig. 1a). Increase in adsorption is due to availability of more vacant sites at initial level which gets filled with the increase in time. The prepared adsorbent is found to be highly efficient to remove RHB as compared to the gelatin/activated carbon composite beads, where the equilibration time is $27 \mathrm{~h}$ (Hayeeye et al. 2016). Ding et al. (2014) also reported that the adsorption of RHB onto treated (b)

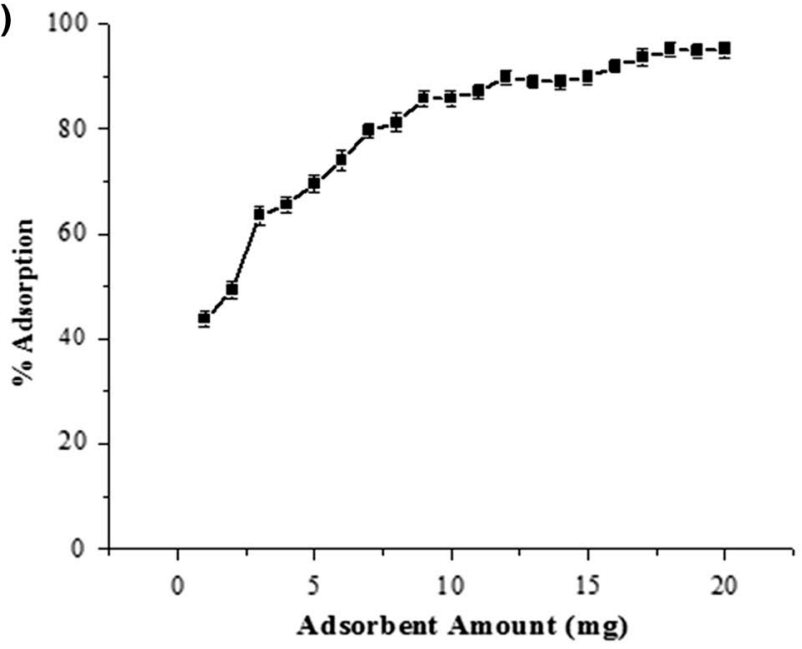

(d)

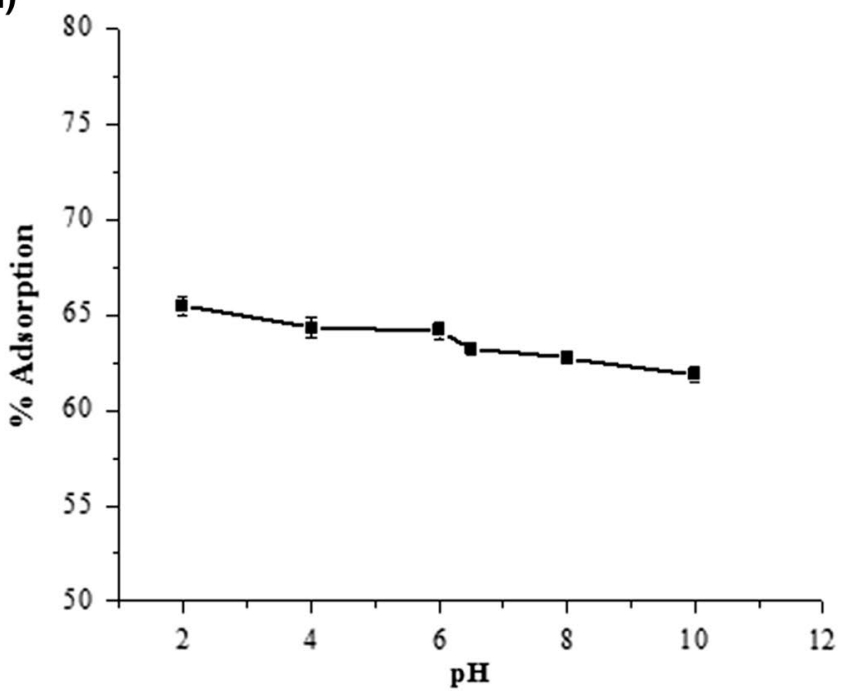

Fig. 1 Influence of various parameters on RHB adsorption. a Contact time, $\mathbf{b}$ adsorbent dose, $\mathbf{c}$ initial concentration, $\mathbf{d}$ solution $\mathrm{pH}$ 
rice husk-based activated carbon was enhanced with the enhancement in contact time and attains equilibrium after a time period of $5 \mathrm{~h}$. The required equilibration time in the present study is better than the equilibrium time required by gelatin or rice husk-based activated carbon. Therefore, for commercial applications, the adsorbent ABPC prepared from banana peel is highly suitable.

\section{Effect of adsorbent dosage}

The recorded results show that RHB removal increases as the amount of absorbent dose increases (Fig. 1b). A linear increase is due to the increase in number of vacant sites available for the adsorption (Gupta 2017). The adsorption of RHB was quantitative at $12 \mathrm{mg}$ adsorbent dose. With further increase in adsorbent dose from $12 \mathrm{mg}$ to $20 \mathrm{mg}$, the dye solution shows a little change in removal of RHB. A similar observation was reported by Uddin et al. (2009) for the adsorption of methylene blue dye on tea waste. Jia and Liu (2017) also reported increase in adsorption percentage of RHB with increase in adsorbent dosage, and the quantitative removal of RHB was achieved at a dose of $30 \mathrm{mg}$. To examine the other parameters related to adsorption of RHB, $3 \mathrm{mg}$ of adsorbent dose was selected.

\section{Effect of concentration of initial dye}

Adsorption of RHB on ABPC was observed with the variation of initial concentration of dye in the range 10-120 $\mathrm{mg} \mathrm{L}^{-1}$. From the attained data, it was clear that there is an increase in adsorption capacity of ABPC with initial concentration of RHB (Fig. 1c). During the process, the immediate relationship between available sites of the adsorbent and dye concentration was established. The experiment reveals that the adsorbate removal percentage decreases with respect to enhancement of initial concentration, which can be attributed to adsorbent site saturation (Gupta 2016; Wasewar 2010). Similar observation was reported by Ding et al. (2014) where the removal percentage of RHB onto treated rice husk-based activated carbon was found to decrease with the increase in concentration of initial dye.

\section{Effect of $\mathrm{pH}$ of solution}

An important parameter which controls the adsorption process is the initial $\mathrm{pH}$ of the dye solution. A slight decrease in the adsorption capacity of ABPC was observed with the increase in $\mathrm{pH}$ of solution (Fig. 1d). A slight higher adsorption was observed at the lowest observed $\mathrm{pH}$, i.e., $\mathrm{pH}$ 2. The RHB structure is dependent to the variation in $\mathrm{pH}$. At $\mathrm{pH}$ below 3 , high $\mathrm{H}^{+}$concentration decreases the available sites for adsorption of species, $\mathrm{RHBH}_{2}{ }^{2+}$, which is positively charged. At $\mathrm{pH}$ near 7, the species, $\mathrm{RHB}^{ \pm}$(zwitter ion), is formed partly and in alkaline conditions, zwitter ion species becomes predominant (Suc and Chi 2016). In the present study, the electrostatic interaction of this species and adsorption sites is low and not the dominant force for the adsorptive removal of RHB onto ABPC. Hydrophobic bonding may be attributed as dominant force for RHB adsorption onto ABPC (Sener and Ozyilmaz 2010). Hence, the adsorption percentage of RHB on ABPC does not show any drastic change neither in acidic nor in basic conditions.

\section{Modeling of adsorption isotherm}

Various researchers developed adsorption isotherms models but among all, Langmuir and Freundlich adsorption isotherm model considered to be the most accepted one. Langmuir adsorption occurs at particular localized adsorption sites, and there is no interaction between adsorbate molecules (Amarasinghe and Williams 2007). The graph was drawn between $1 / q_{\mathrm{e}}$ and $1 / C_{\mathrm{e}}$ (Fig. 2a) where $q_{\mathrm{e}}$ and $C_{\mathrm{e}}$ have their significant meaning. Adsorption constant $Q^{\mathrm{o}}$ and $\mathrm{b}$ can be calculated from the equation of slope and intercept of the straight line, respectively. The straight lines were also obtained when the plots $q_{\mathrm{e}}$ versus $C_{\mathrm{e}}$ were made for the Freundlich adsorption isotherms (Fig. 2b). The constants $\mathrm{n}$ and $\mathrm{K}_{\mathrm{f}}$ are calculated using these plots. Table 1 represents the Freundlich and Langmuir constants along with $\mathrm{R}^{2}$ at different temperatures. The values of $R^{2}$ suggest that the data are well fitted with Langmuir isotherm. The strong tendency of the process for the monolayer adsorption is also reported by various authors (Mckay et al. 1987; Ho and McKay 1999).

\section{Kinetics of adsorption}

Various models such as intra-particle diffusion, pseudo-firstorder, and pseudo-second-order models are applied to assess the adsorption of RHB on ABPC.

Lagergren rate equation (pseudo-first-order model) can be given as follows:

$\frac{\mathrm{d} q}{\mathrm{~d} t}=k_{\mathrm{f}}\left(q_{\mathrm{e}}-q\right)$

where adsorbate amount adsorbed at ' $t$ ' time $\left(\mathrm{mg} \mathrm{g}^{-1}\right)$ is represented by $q, q_{\mathrm{e}}$ is equilibrium adsorption capacity $\left(\mathrm{mg} \mathrm{g}^{-1}\right)$, the pseudo-first-order model constant was represented by $\mathrm{k}_{\mathrm{f}}$, and $\mathrm{t}$ represents time. Applying the definite integration and initial condition that $q=0$ at $t=0$ and $q=q$ at $\mathrm{t}=\mathrm{t}$, equation changes as follows (Wasewar 2010):

$\log \left(q_{\mathrm{e}}-q\right)=\log q_{\mathrm{e}}-\left(k_{\mathrm{f}} / 2.303\right) * t$ 

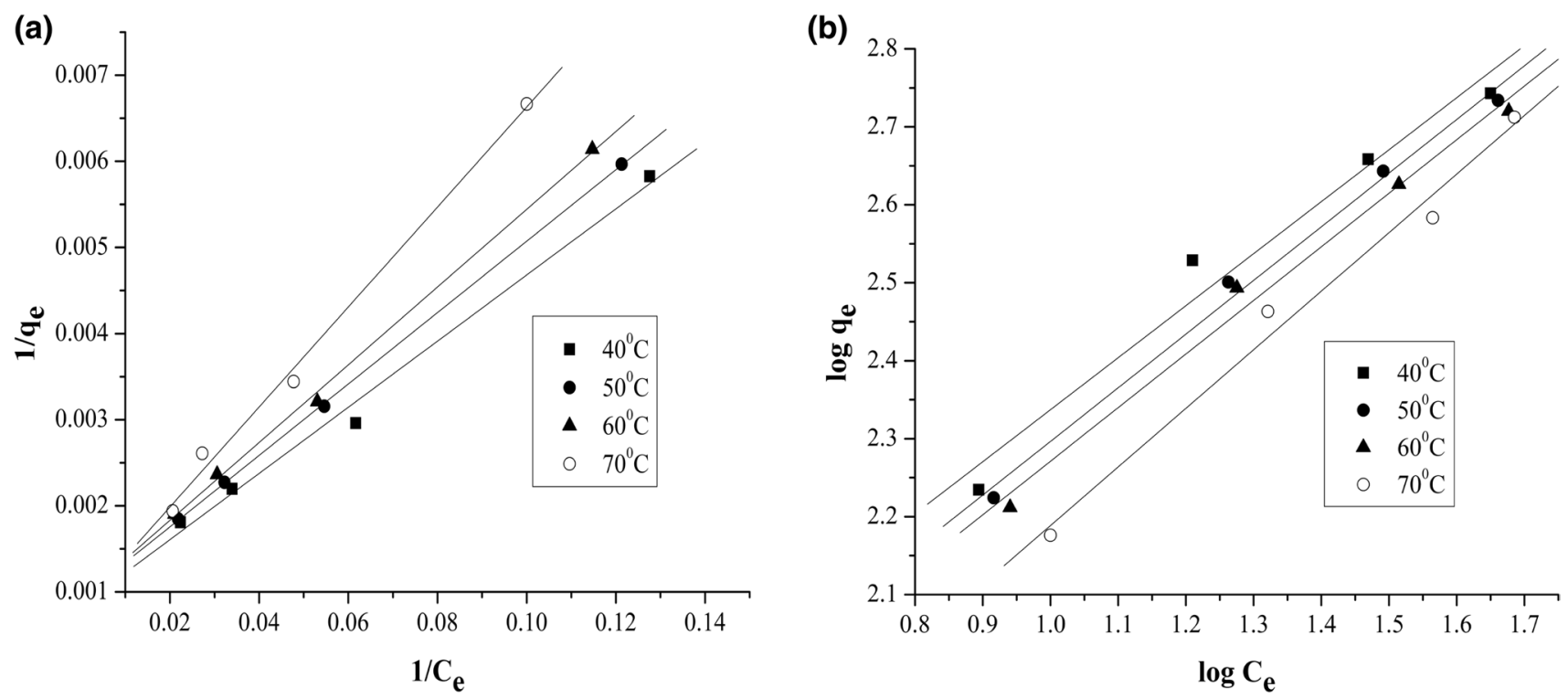

Fig. 2 Adsorption isotherms for RHB at different temperatures. a Langmuir isotherms. b Freundlich isotherms

Table 1 Langmuir and Freundlich parameters for the adsorption of RHB on ABPC

\begin{tabular}{|c|c|c|c|c|c|c|c|c|c|}
\hline \multicolumn{5}{|c|}{ Langmuir parameters } & \multicolumn{5}{|c|}{ Freundlich parameters } \\
\hline \multirow[t]{2}{*}{ Term } & \multicolumn{4}{|l|}{ Values } & \multirow[t]{2}{*}{ Term } & \multicolumn{4}{|l|}{ Values } \\
\hline & $40{ }^{\circ} \mathrm{C}$ & $50{ }^{\circ} \mathrm{C}$ & $60{ }^{\circ} \mathrm{C}$ & $70^{\circ} \mathrm{C}$ & & $40{ }^{\circ} \mathrm{C}$ & $50{ }^{\circ} \mathrm{C}$ & $60^{\circ} \mathrm{C}$ & $70^{\circ} \mathrm{C}$ \\
\hline$b(\mathrm{~L} / \mathrm{mg})$ & 40.47 & 38.33 & 37.92 & 34.66 & $1 / n$ & 0.8786 & 1.0258 & 1.0266 & 1.4065 \\
\hline$R^{2}$ & 0.9795 & 0.9842 & 0.9715 & 0.9552 & $R^{2}$ & 0.9341 & 0.9781 & 0.9159 & 0.8932 \\
\hline$Q^{\mathrm{o}}(\mathrm{mg} / \mathrm{g})$ & 952.38 & 833.33 & 714.28 & 666.66 & $k_{\mathrm{f}}$ & 28.31 & 18.37 & 16.92 & 5.4212 \\
\hline
\end{tabular}

(a)

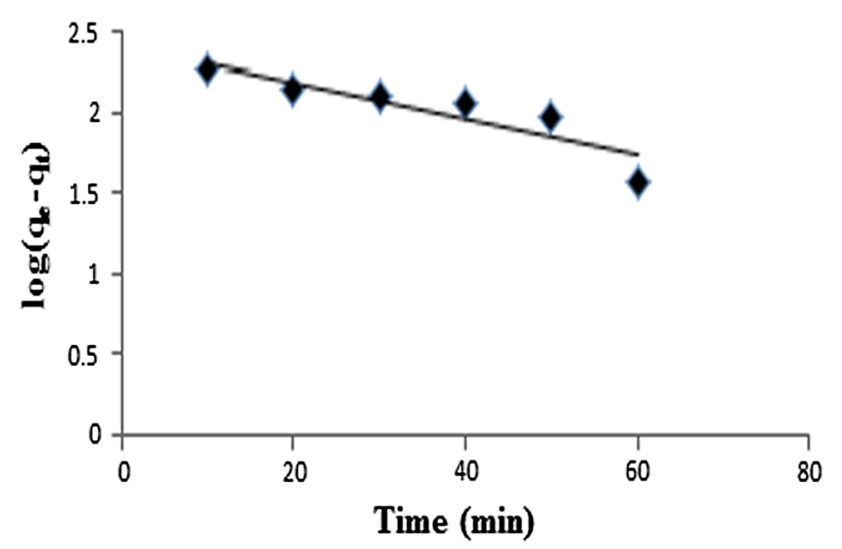

(b)

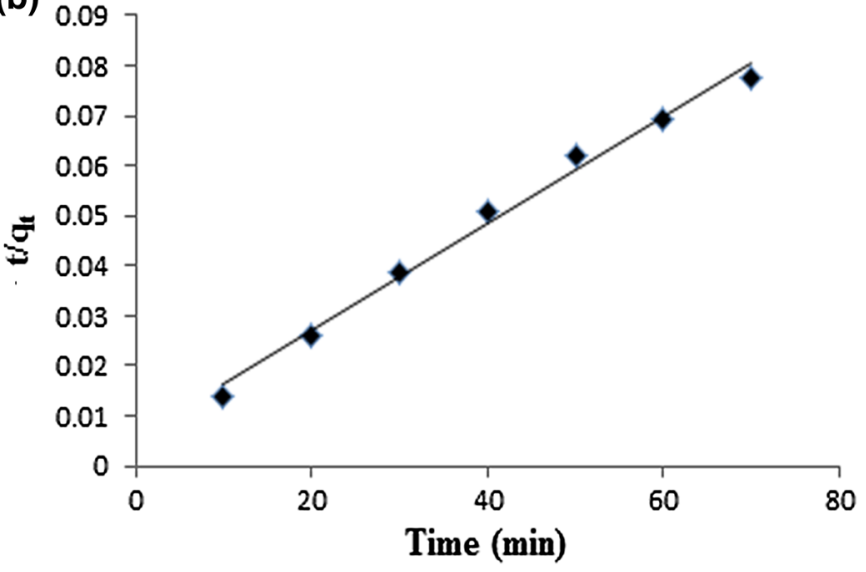

Fig. 3 Different kinetic models for adsorption of RHB on ABPC. a Pseudo-first order. b Pseudo-second order

A plot between $\log \left(q_{\mathrm{e}}-q\right)$ versus $t$ was drawn to study the pseudo-first-order kinetic model (Fig. 3a) and to evaluate the corresponding parameters.

The pseudo-second-order rate equation is given as follows: $\frac{\mathrm{d} q}{\mathrm{~d} t}=k_{2}\left(q_{\mathrm{e}}-q\right)^{2}$

where $q_{\mathrm{e}}$ and $q$ denote RHB amount adsorbed on adsorbent $(1 \mathrm{~g})$ upon equilibrium and on ' $t$ ' time, respectively, and 
Table 2 Kinetic parameters for pseudo-first-order, pseudo-secondorder, and intra-particle diffusion models

\begin{tabular}{|c|c|c|c|c|c|}
\hline \multicolumn{2}{|c|}{$\begin{array}{l}\text { Pseudo-first-order } \\
\text { model }\end{array}$} & \multicolumn{2}{|c|}{$\begin{array}{l}\text { Pseudo-second-order } \\
\text { model }\end{array}$} & \multicolumn{2}{|c|}{$\begin{array}{l}\text { Intra-particle } \\
\text { diffusion models }\end{array}$} \\
\hline$K_{1}$ & $R^{2}$ & $K_{2}$ & $R^{2}$ & $K_{\mathrm{i}}$ & $R^{2}$ \\
\hline $2.64 \times 10^{-2}$ & 0.8081 & $2.20 \times 10^{-4}$ & 0.9909 & 35.48 & 0.9556 \\
\hline
\end{tabular}

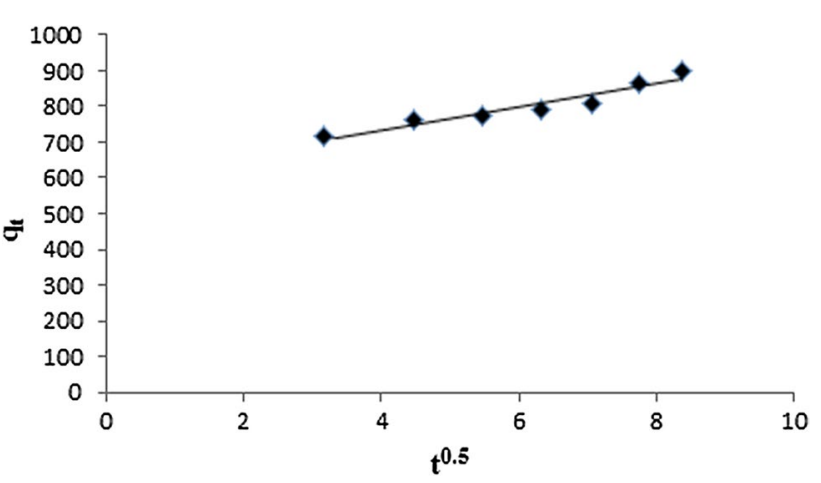

Fig. 4 Intra-particle diffusion model for RHB-ABPC interaction

$k_{2}$ is rate constant of pseudo-second-order model $\left(\mathrm{g} \mathrm{mg}^{-1}\right.$ $\mathrm{min}^{-1}$ ). Applying boundary condition and integrating at $t=0$ to $t=t, q=o$ to $q=q$ (Wasewar, 2010), the equation given as follows:

$\frac{t}{q}=1 / k_{2} q_{\mathrm{e}}^{2}+\left(1 / q_{\mathrm{e}}\right) t$

Rate constant of pseudo-second-order $\left(k_{2}\right)$ is determined using plot of $t / q$ versus $t$ (Fig. 3b). The values of rate constant for pseudo-first-order and pseudo-secondorder models are $2.64 \times 10^{-2}$ and $2.20 \times 10^{-4}$, respectively (Table 2). The $R^{2}$ values obtained in both the cases suggest better applicability of pseudo-second-order model (0.9909) than pseudo-first-order model (0.8081). The results suggest physiological interaction between two phases is responsible for removal of RHB from aqueous media (Hayeeye et al. 2016).

\section{Intra-particle diffusion model}

Intra-particle diffusion model is applicable in adsorption process when plot made between adsorbate uptake and square root of time is linear (Fig. 4). Two cases may arise: (1) straight line passing through the origin, which represents the rate-controlling step (Wasewar 2010), (2) straight line not passing through origin which represents the presence of some degree of boundary layer control. On the basis of the results obtained (Fig. 4), it can be said that the intra-particle diffusion model is not only rate-limiting step, and other simultaneously operating kinetics models also interfere to control the rate of adsorption (Ozcan et al. 2005).

The Waber-Morris plot is an empirically found relationship which is common to most adsorption process. This plot helps in uptake which varies almost proportionally with $t^{1 / 2}$ rather than with the contact time $t$ (Weber and Morris 1963).

$q=k_{i} t^{1 / 2}+C$

where $k_{\mathrm{i}}$ refers to diffusion constant in intra-particle model and values of intercept $\mathrm{C}$ explain the boundary layer thickness. The larger the value of ' $C$,' the greater the influence of boundary layer (Kannan and Sundaram 2001). The values of diffusion constant and correlation coefficient for intraparticle diffusion model are 35.48 and 0.9556 (Table 2). The model in the present study reveals the deviation of straight line from origin for adsorption of RHB onto ABPC. The deviation of straight line from origin proves that the pore diffusion was not only the rate-controlling step (Poots et al. 1978).

\section{Thermodynamic parameters}

The thermodynamic parameters for RHB adsorption onto ABPC were investigated at various temperatures. RHB adsorption was performed with $3 \mathrm{mg}$ of adsorbent in a conical flask. The data were analyzed for the remaining concentration of RHB in the solution at different temperatures. The adsorption capacity decreases with temperature in the range $40-70{ }^{\circ} \mathrm{C}$ indicating the adsorption favors exothermic process.

The spontaneity and feasibility of adsorption can be depicted through various thermodynamic parameters such as entropy change, $\Delta S^{\circ}$, Gibb's free energy change $\Delta G^{\circ}$, enthalpy change $\Delta H^{\circ}$. Langmuir isotherms and Van't Hoff equation hold good to evaluate the thermodynamic parameters $\left(\Delta H^{\mathrm{o}}, \Delta S^{\mathrm{o}}, \Delta G^{\mathrm{o}}\right)$ using the following equations for the adsorption of RHB on ABPC (Hayeeye et al. 2016).

$\ln k_{\mathrm{c}}=\Delta S^{o} / R-\Delta H^{o} / R T$

where $k_{\mathrm{c}}$ is the ratio of $C_{\mathrm{A}}$ to $C_{\mathrm{e}}$ where $C_{\mathrm{A}}$ is the solid-phase concentration of Rhodamine $\mathrm{B}$ in solution and $C_{\mathrm{e}}$ is RHB concentration on equilibrium, $\mathrm{T}$ is temperature in Kelvin and $R$ represents gas constant $\left(8.314 \mathrm{~J} \mathrm{~K}^{-1} \mathrm{~mol}^{-1}\right)$. The value of $\Delta \mathrm{H}^{\mathrm{o}}$ and $\Delta \mathrm{S}^{\mathrm{o}}$ may be calculated from slope-intercept of Van't Hoff plot. The value of $\Delta G^{\mathrm{o}}$ shows the spontaneity and feasibility of the adsorption process.

$\Delta G=-R T \ln K_{a}$

$\Delta G^{o}=\Delta H^{o}-T \Delta S^{\circ}$ 
$\Delta S^{\circ}=-\left(\Delta G^{o}-\Delta H^{o}\right) / T$

where $K_{\mathrm{a}}$ is Langmuir equilibrium constant. $\Delta G^{\mathrm{o}}$ values were evaluated through Langmuir equilibrium constant at different temperatures. The graph was found to be linear between $\Delta G^{\circ}$ and $T$. The values of $\Delta G^{\circ}$ at $40,50,60$, and $70{ }^{\circ} \mathrm{C}$ were found to be $-9.62,-9.79,-10.06$, and $-10.11 \mathrm{~kJ} \mathrm{~mol}^{-1}$, respectively. The values of $\Delta S^{\circ}$ and $\Delta H^{\mathrm{o}}$ were observed to be $2 \times 10^{-2} \mathrm{~kJ} \mathrm{~K}^{-1} \mathrm{~mol}^{-1}$ and $-8.95 \mathrm{~kJ} \mathrm{~mol}^{-1}$, respectively. The negative values of $\Delta G^{0}$ reveal the spontaneity of RHB adsorption on ABPC. Furthermore, the negative enthalpy proves the adsorption process to be exothermic.

\section{Conclusion}

The synthesized activated banana peel carbon (ABPC) was utilized as cost-effective absorbent for the decontamination of Rhodamine B from aqueous media. The BET surface area of the synthesized adsorbent was found to be $>900 \mathrm{~m}^{2} / \mathrm{g}$. The synthesized ABPC is efficient for the removal of RHB in acidic and basic conditions. Effect of contact time shows that initially adsorption occurs at rapid rate, then it slows down, a slightly higher adsorption was observed at $\mathrm{pH}=2$, and adsorption of RHB was quantitative at $12 \mathrm{mg}$ adsorbent dose. The results indicate that both the Freundlich and Langmuir models can be used to fit the data and estimate the model parameters. The removal percentage achieved for the dye was $81.9-85.6 \%$ by the batch method. In the present study, pseudo-second-order kinetic model $\left(R^{2}>0.99\right)$ was best fitted for the adsorption of RHB on ABPC. The study of intra-particle models reveals that pore diffusion was not only the rate-controlling step. The negative value of enthalpy change in the temperature range $40-70{ }^{\circ} \mathrm{C}$ indicates that the adsorption favors exothermic process. The present work explores the applicability of ABPC for the highly efficient and economic removal of dyes from aqueous media. The study of kinetics and thermodynamics of the process is useful for the assessment of decontamination behavior, spontaneous nature, temperature dependence, and feasibility before commercial production of activated carbon.

Acknowledgments This research did not receive any specific grant from funding agencies in the public, commercial, or not-for-profit sectors. We are thankful to the reviewers and editor for giving constructive comments to improve the quality of the paper.

\section{Compliance with ethical standards}

Conflict of interest The authors declare that they have no known competing financial interests or personal relationships that could have appeared to influence the work reported in this paper.
Open Access This article is licensed under a Creative Commons Attribution 4.0 International License, which permits use, sharing, adaptation, distribution and reproduction in any medium or format, as long as you give appropriate credit to the original author(s) and the source, provide a link to the Creative Commons licence, and indicate if changes were made. The images or other third party material in this article are included in the article's Creative Commons licence, unless indicated otherwise in a credit line to the material. If material is not included in the article's Creative Commons licence and your intended use is not permitted by statutory regulation or exceeds the permitted use, you will need to obtain permission directly from the copyright holder. To view a copy of this licence, visit http://creativecommons.org/licenses/by/4.0/.

\section{References}

Amarasinghe BMWPK, Williams RA (2007) Tea waste as a low cost adsorbent for the removal of $\mathrm{Cu}$ and $\mathrm{Pb}$ from wastewater. Chem Eng J 132:299-309

Chang TL, Cheung HC (1992) Solvent effects on the photoisomerization rates of the zwitterionic and the cationic forms of rhodamine B in protic solvents. J Phys Chem 96(12):4874-4878

Ding L, Zou B, Gao W, Wang Z, Guo Y, Wang X, Liu Y (2014) Adsorption of Rhodamine-B from aqueous solution using treated rice husk-based activated carbon. Colloids Surfaces A446:1-7

Gupta H (2016) Photocatalytic degradation of phenanthrene in the presence of akaganeite nano-rods and the identification of degradation products. RSC Adv 6:112721-112727

Gupta H (2017) PAH determination in effluent and sludge samples of paper industry. Environ Technol Innov 9:115-121

Gupta H (2018) Anthracene removal from water onto activated carbon derived from vehicular tyre. Sep Sci Technol 53(4):613-625

Gupta B, Gupta H (2015a) Iron oxide mediated degradation of mutagen pyrene and determination of degradation products. Int J Environ Sci Dev 6:908-912

Gupta H, Gupta B (2015b) Photocatalytic degradation of polycyclic aromatic hydrocarbon benzo[a]pyrene by iron oxides and identification of degradation products. Chemosphere 138:924-931

Gupta H, Gupta B (2016a) Vehicular tire as potential adsorbent for the removal of polycyclic aromatic hydrocarbons. Polycycl Aromat Compd 38(4):354-368

Gupta H, Gupta B (2016b) Adsorption of polycyclic aromatic hydrocarbons on banana peel activated carbon. Desalin Water Treat 57:9498-9509

Gupta VK, Mittal A, Krishnan L, Gajbe V (2004) Adsorption kinetics and column operations for the removal and recovery of malachite green from wastewater using bottom ash. Sep Purif Technol 40:87-96

Gupta VK, Ali I, Saini VK, Tom VG, Bruggen BVD, Vandecasteele C (2005) Removal of dyes from wastewater using bottom ash. Ind Eng Chem Res 44:3655-3664

Hayeeye F, Sattar M, Chinpa W, Sirichote O (2016) Kinetics and thermodynamics of Rhodamine B adsorption by gelatin/activated carbon composites beads. Colloids Surf A Physicochem Eng Asp 513:259-266

Ho YS, McKay G (1999) Pseudo-second order model for sorption processes. Process Biochem 34:451-465

Jia H, Liu N (2017) Adsorptive removal of Rhodamine B from aqueous solution by nanoporous polydivinylbenzene. Water Sci Tech 75(7):1651-1658

Kannan N, Sundaram MM (2001) Kinetics and mechanism of removal of methylene blue by adsorption on various carbons - a comparative study. Dyes Pigm 51:25-40 
Kumar R, Gupta B, Gupta H, Rani M (2014a) Distribution of persistent organic pollutants in urban aquatic systems. Int J Sci Res Env Sci 2:233-243

Kumar R, Rani M, Gupta H, Gupta B (2014b) Trace metal fractionation in water and sediments of an urban river stretch. Chem Spec Bioavailab 26(4):200-209

Kumar A, Sharma MP, Rai SP (2017a) A novel approach for river health assessment of Chambal using fuzzy modeling. India Desalin Water Treat 58:72-79

Kumar A, Sharma MP, Taxak AK (2017b) Analysis of water environment changing trend in Bhagirathi tributary of Ganges in India. Desalin Water Treat 63:55-62

Kumar R, Rani M, Gupta H, Gupta B, Park D, Jeon B-H (2017c) Distribution of trace elements in flowing surface waters: effect of seasons and anthropogenic practices in India. Intern J Environ Anal Chem 97(7):637-656

Kumar A, Khan M, He J, Lo IMC (2019a) Visible-light-driven $\mathrm{N}-\mathrm{TiO}_{2} @ \mathrm{SiO}_{2} @ \mathrm{Fe}_{3} \mathrm{O}_{4}$ magnetic nanophotocatalysts: synthesis, characterization, and photocatalytic degradation of PPCPs. J Hazard Mater 370:108-116

Kumar A, Khan M, Zeng X, Lo IMC (2019b) Development of g-C3N4/ $\mathrm{TiO} / \mathrm{Fe} 3 \mathrm{O} 4 @ \mathrm{SiO} 2$ heterojunction via sol-gel route: a magnetically recyclable direct contact Z-scheme nanophotocatalyst for enhanced photocatalytic removal. Chem Eng J 353:645-656

Kumar A, Khan M, He J, Lo IMC (2020a) Recent developments and challenges in practical application of visible-light-driven $\mathrm{TiO}_{2}-$ based heterojunctions for PPCP degradation: a critical review. Water Res 170(1):115356

Kumar A, Khan M, He J, Lo IMC (2020b) Visible-light-driven magnetically recyclable terephthalic acid functionalized $\mathrm{g}-\mathrm{C}_{3} \mathrm{~N}_{4} /$ $\mathrm{TiO}_{2}$ heterojunction nanophotocatalyst for enhanced degradation of PPCPs. Appl Catal B 270(5):118898

Kumar A, MMS C-P, Chaturvedi AK, Shabnam AA, Subrahmanyam G, Mondal R, Gupta DK, Malyan SK, Kumar S, Khan S, Yadav KK (2020c) Lead toxicity: health hazards, influence on food chain, and sustainable remediation approaches. Int J Environ Res Public Health 17:2179

Lafi WK (2001) Production of activated carbon from acorns and olive seeds. Biomass Bioenergy 20:57-62

McKay G, Geundi MEL, Nassar MM (1987) Equilibrium studies during the removal of dyestuffs from aqueous solution using bagasse pith. Water Res 21(12):1513-1520

Mishra S, Maiti A (2016) The efficiency of Eichhornia crassipes in the removal of organic and inorganic pollutants from wastewater: a review. Environ Sci Pollut Res 24(9):7921-7937

Mishra S, Nayak J, Maiti A (2020) Bacteria-mediated bio-degradation of reactive azo dyes coupled with bio-energy generation from model wastewater. Clean Technol Environ Policy 22:651-667

Mohapatra D, Mishra S, Sutar N (2010) Banana and its by-product utilisation: an overview. J Sci Ind Res 69:323-329

Nagaraja R, Kottam N, Girija CR, Nagabhushana BM (2012) Photocatalytic degradation of Rhodamine B dye under UV/solar light using $\mathrm{ZnO}$ nanopowder synthesized by solution combustion route. Powder Technol 215-216:97

Ozcan A, Ozcan AS, Tunali S, Akar T, Kiran I (2005) Determination of the equilibrium, kinetic and thermodynamic parameters of adsorption of copper (II) ions onto seeds of Capsicum annuum. J Hazard Mater B124:200-208

Paliwal R, Uiyal S, Verma M, Kumar A, Rai JPN (2015) Process optimization for biodegradation of black liquor by immobilized novel bacterial consortium. Desalin Water Treat 56(2):1-12
Poots VJP, McKay G, Healy JJ (1978) Removal of basic dye from effluent using wood as an adsorbent. Water Pollut Control Fed 50(5):926-993

Posa VRP, Annavaram V, Koduru JR, Bobbala P, Madhavi V, Somala AR (2016) Preparation of graphene- $\mathrm{TiO}_{2}$ nanocomposite and photocatalytic degradation of Rhodamine-B under solar light irradiation. J Exp Nanosci 11(9):722-736

Rahman IA, Saad B, Shaidan S, Rizal ESS (2005) Adsorption characteristics of malachite green on activated carbon derived from rice husks produced by chemical-thermal process. Bioresour Technol 96:1578-1583

Salam NA, Buhari M (2014) Adsorption of alizarin and fluorescein dyes on adsorbent prepared from mango seed. Pac J Sci Technol 15:232-244

Salleh MAM, Mahmoud DK, Karim WAWA, Idris A (2011) Cationic and anionic dye adsorption by agricultural solid wastes: a comprehensive review. Desalination 280:1-13

Sener S, Ozyilmaz A (2010) Adsorption of naphthalene onto sonicated talc from aqueous solutions. Ultrason Sonochem 17:932-938

Shaikh MS, Qureshi K, Bhatti I (2011) Utilization of tea waste for the removal of arsenic (III) from aqueous solution. Sidh Univ Res J (Sci Ser) 43(1):97-104

Suc NV, Chi DK (2016) Removal of Rhodamine B from aqueous solution via adsorption onto microwave activated rice husk ash. J Dispers Sci Technol 38:216-222

Sundararajan M, Sailaja V, Kennedy LJ, Vijaya JJ (2017) Photocatalytic degradation of rhodamine $\mathrm{B}$ under visible light using nanostructured zinc doped cobalt ferrite: kinetics and mechanism. Ceram Int 43(1):540-548

Tan IAW, Ahmad AL, Hameed BH (2008) Adsorption of basic dye on high-surface-area activated carbon prepared from coconut husk: equilibrium, kinetic and thermodynamic studies. J Hazard Mater 154:337-346

Uddin MT, Islam MA, Mahmud S, Rukanuzzaman M (2009) Adsorptive removal of methylene blue by tea waste. J Hazard Mater 164:53-60

Wasewar K (2010) Adsorption of metals onto tea factory waste: a review. Int J Recent Res Appl Stud 3:303-322

Weber WJ, Morris JC (1963) Kinetics of adsorption on carbon from solution. J Sanit Eng Div 89(2):31-60

Weis JS, Weis P (2004) Metal uptake, transport and release by wetland plants: implications for phytoremediation and restoration. Environ Int 30:85-700

Yao S, Xu T, Zhao N, Zhang L, Huo Q, Liu Y (2017) An anionic metal-organic framework with ternary building units for rapid and selective adsorption of dyes. Dalton Trans 46:3332-3337

Zhu H, Jiang R, Li J, Fu Y, Jiang S, Yao J (2017) Magnetically recyclable $\mathrm{Fe}_{3} \mathrm{O}_{4} / \mathrm{Bi}_{2} \mathrm{~S}_{3}$ microspheres for effective removal of Congo red dye by simultaneous adsorption and photo catalytic regeneration. Sep Purif Technol 179:184-193

Publisher's Note Springer Nature remains neutral with regard to jurisdictional claims in published maps and institutional affiliations. 